\title{
Evaluation of Corrosion Resistance of Multi-Layered Ti/Glass-Ceramic Interfaces by Electrochemical Impedance Spectroscopy
}

\author{
E. Ariza ${ }^{1, a}$ and L.A. Rocha ${ }^{1,2, b}$ \\ ${ }^{1}$ CIICS - Centro de Investigação em Interfaces e Comportamento de Superfícies, Universidade do \\ Minho, Campus de Azurém, P-4800-058 Guimarães, Portugal \\ ${ }^{2}$ DEM - Departamento de Engenharia Mecânica, Universidade do Minho, Campus de Azurém, P- \\ 4800-058 Guimarães, Portugal \\ aedith@dem.uminho.pt; 'rrocha@dem.uminho.pt
}

Keywords: Metal/Ceramic interfaces. Active metal brazing. EIS.

\begin{abstract}
Practical applications of metal/ceramic joints can be found in the biomedical field regarding the encapsulation of implantable telemetric devices, the fabrication of crowns and bridges for dental restoration, or in the production of drug delivery systems, biomedical sensors and electrodes. Most of metal/ceramic joints are produced by the active metal brazing technique, which originates a multi-layered interface which should be able of accommodating the abrupt electronic, crystallographic, chemical, mechanical and thermo-mechanical discontinuity that characterize these systems. Additionally, when considering biomedical applications, corrosion resistance becomes of prime importance.

In this work, the corrosion resistance of Ti/glass-ceramic interfaces obtained by active metal brazing was evaluated by electrochemical impedance spectroscopy (EIS) tests. The electrochemical behaviour of the interface was monitored, as a function of time, in a simulated physiological solution at room temperature. In order to evaluate the contribution of each layer and galvanic interactions between them, to the degradation mechanism of the interface, individual samples, representative of reaction layers present at the interface, were fabricated and electrochemically tested.

Results show that the corrosion behaviour, of the whole interface was strongly influenced by the chemical composition of its constitutive layers. Thus, layers containing high contents of both titanium and silver showed a polarisation resistance increase with the immersion time, as a result of the formation of a thermodynamically stable passive film. On the other hand, the copper rich layer, appears to be the main responsible for the interface degradation. In fact, for high immersion times, an instable passive film is formed and, as a consequence, large amounts of copper are released. Galvanic interactions between the copper and the silver rich layers where also identified.
\end{abstract}

\section{Introduction}

In the last years metal/ceramic (M/C) joints have emerged as very important system to be used in diverse biomedical applications. One of the most important joining techniques used to produce these joints is the active metal brazing procedure, which involves a brazing alloy, characterized by its low melting point, which is expected to promote a better wettability between both materials, metal and ceramic. From the corrosion point of view, one of the drawbacks of this methodology is the formation of a complex interface which, most of the times, is the critical region of the component $[1,2]$. It is recognized that when a multi-layered metal/ceramic interface is obtained, the degradation of the interface may be dictated by complex microscopic galvanic interactions between layers. As a consequence, knowledge of the chemical characteristics and distribution of the reaction products at the interface is needed in order to control the general properties of the joints.

The quantitative evaluation of corrosion properties, using conventional electrochemical measurements, i.e. DC measurements techniques, do not provide complete information about the corrosion mechanisms and, some times, it was found that these techniques are difficult to use in 
systems containing reaction layers of diminutive dimensions. In contrast, the EIS technique represents an attractive method to be used in the understanding of degradation mechanisms of these complex interface systems. Moreover, EIS measurements performed at the corrosion potential do not introduce any significant acceleration of the corrosion phenomena and can be used to study the evolution of corrosion phenomena with the time.

In this work, the corrosion behaviour of Ti/Glass-ceramic interfaces, obtained by active metal brazing, was evaluated and experimentally modelled by electrochemical techniques. For this propose both, the interface and standard samples fabricated to simulate the chemical composition of the layers found at the interface, were studied by EIS, when immersed in a simulated physiological solution. In addition, potentiodynamic polarisation tests were used as a complementary characterisation technique. The EIS data were interpreted using an electrochemical equivalent circuit that allowed a better understanding of the corrosion mechanisms occurring at the interface.

\section{Materials and Methods}

Fabrication Technique, Chemical and Morphological Characterisation. Fluorosilicate machinable glass-ceramic (Macor ${ }^{\circledR}$ from Corning Glass Works) and commercial pure titanium (ASTM grade II) rods, $13 \mathrm{~mm}$ in diameter, were used as base material to produce the metal/ceramic interfaces. Active metal brazing was used as joint technique and the $\mathrm{CB} 4$ alloy $(70.5 \mathrm{Ag}-26.5 \mathrm{Cu}-$ 3.0Ti, from Degussa, Germany) was selected as brazing alloy.

Active metal brazing was carried out in a high vacuum Termolab resistance furnace. The static pressure applied to the metal/ceramic system during the thermal cycle was $0.24 \mathrm{Kg} . \mathrm{cm}^{-2}$. Samples heated up to $300^{\circ} \mathrm{C}$ at a heating rate of $5^{\circ} \mathrm{C} \cdot \mathrm{min}^{-1}$, were kept at that temperature during $30 \mathrm{~min}$. Then, samples were heated up to $800^{\circ} \mathrm{C}$ at the same heating rate and kept at that temperature during 15 minutes, finally they were cooled down to room temperature $\left(2^{\circ} \mathrm{C} \cdot \mathrm{min}^{-1}\right)$.

Chemical composition and morphology of the Ti/Glass-ceramic interface were studied by scanning Electron Microscopy (SEM) and Energy Dispersive Spectroscopy (EDS) analysis. In order to minimise excitation volume, all EDS analysis were performed under an acceleration voltage of $15 \mathrm{KeV}$. Based on these analyses, standard samples simulating the composition of the principal layers founded at the interface were fabricated in an arc-melting furnace, under an argon protective atmosphere. These standard samples were also characterized by SEM and EDS analysis before and after to the electrochemical test.

Electrochemical Test. The corrosion behaviour of the interface and its constitutive layers was studied in a Hank's Balanced Salt Solution (HBSS), H-8264 from Sigma ${ }^{\circledR}$, with a pH of 7.3, at room temperature. For this propose open circuit potential, electrochemical impedance spectroscopy and potentiodynamic polarisation tests were carried out.

A PGZ100 Voltalab potentiostat (Radiometer, Denmark), controlled by the VoltaMaster-4 software, was used in the EIS experiments. EIS measurements were performed at increasing immersion times (one hour up to ten days) in the frequency range from $100 \mathrm{kHz}$ to $5 \mathrm{mHz}$, with an AC signal wave amplitude of $10 \mathrm{mV}$ applied at the corrosion potential. The analysis of EIS results was performed through EIS data simulation using the ZView2 software, in order to obtain an equivalent circuit model that describes the corrosion behaviour of the interface.

A PGP201 potentiostat/galvanostat (Radiometer, Denmark), controlled by the VoltaMaster software, was used in potentyodinamic polarisation measurements. The samples were polarised from $-600 \mathrm{mV}$ up to $2000 \mathrm{mV}$ at a scan rate of $2 \mathrm{mV} \cdot \mathrm{s}^{-1}$.

Before EIS and potentiodynamic polarisation measurements, the open-circuit potential $\left(\mathrm{E}_{\mathrm{corr}}\right)$ of the samples was monitored during $60 \mathrm{~min}$. In all experiments a saturated calomel electrode (SCE) was used as reference electrode and a wire of platinum, with an exposed area of $1 \mathrm{~cm}^{2}$, was employed as counter electrode. Previously to corrosion tests the surface of the samples was abraded with $\mathrm{SiC}$ paper followed by polishing with diamond paste. All samples were ultrasonically cleaned in ethanol (15 $\mathrm{min})$ and distilled water $(20 \mathrm{~min})$ and finally dried at room temperature. 


\section{Results and Discussion}

\section{Chemical and Morphological Characterisation of the Interface.}

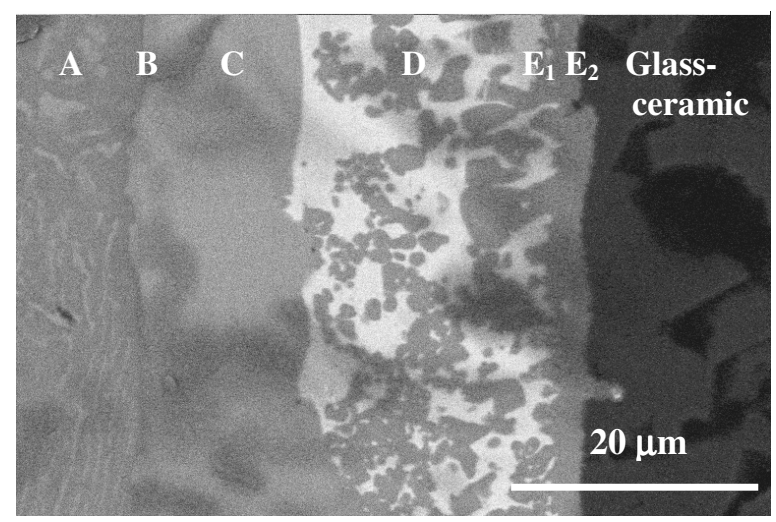

Fig. 1: SEM micrograph of Ti/Glass-ceramic interface and its constitutive layers.
Fig. 1, shows a representative SEM micrograph of the interface. As previously described by Rocha [2, 3], who studied M/C joints produced with the same methodology using different brazes, the interface is constituted by several reaction layers. At the titanium side diffusion of $\mathrm{Cu}$ into $\mathrm{Ti}$ was observed. This diffusion process is considered as the responsible for the joining with Ti. As a consequence, two principal Ti-rich layers are formed (layers A and B). Near these two layers, a third $\mathrm{Cu}$-rich layer (layer $\mathrm{C}$ ) appears to collect the higher content of this element. Adjacent at the layer $\mathrm{C}$, silver is segregated into the intermediate layer (layer D). Finally, at the glass-ceramic side (layers $E_{1}$ and $E_{2}$ ) accumulation of $\mathrm{Ti}$ and the presence of $\mathrm{Si}$, was detected. In fact, the bonding with the glass-ceramic occurs because $\mathrm{Ti}$ is expected to reduce $\mathrm{SiO}_{2}$ giving origin to both, Ti oxides and $\mathrm{Ti}$ silicides, these being the main constituents of layers $\mathrm{E}_{1}$ and $\mathrm{E}_{2}$ [2].

As a result of the chemical characterisation by EDS of the interface, six standard samples representative of the most important layers presented at the $\mathrm{M} / \mathrm{C}$ interface, were prepared. They were named $\mathrm{A}, \mathrm{B}, \mathrm{C}, \mathrm{D}, \mathrm{E}_{1}$ and $\mathrm{E}_{2}$, being $\mathrm{A}$ the layer near to the Ti face and $\mathrm{E}_{2}$ the layer placed near to the glass-ceramic side. Table 1, shows the chemical composition obtained by EDS analysis for the different layers of the interface and for the standard samples fabricated to simulate the same.

Table 1: Chemical composition of individual samples fabricated to simulate interfacial layers.

\begin{tabular}{|c|c|c|c|c|c|c|c|c|}
\hline \multirow[b]{2}{*}{ Layer } & \multicolumn{2}{|c|}{$\begin{array}{c}\mathrm{Ti} \\
\text { Atomic } \%\end{array}$} & \multicolumn{2}{|c|}{$\begin{array}{c}\mathrm{Cu} \\
\text { Atomic } \%\end{array}$} & \multicolumn{2}{|c|}{$\begin{array}{c}\text { Ag } \\
\text { Atomic } \%\end{array}$} & \multicolumn{2}{|c|}{$\begin{array}{c}\mathrm{Si} \\
\text { Atomic } \%\end{array}$} \\
\hline & $\begin{array}{c}\text { EDS } \\
\text { Interface }\end{array}$ & $\begin{array}{c}\text { EDS } \\
\text { Standard } \\
\text { sample }\end{array}$ & $\begin{array}{c}\text { EDS } \\
\text { Interface }\end{array}$ & $\begin{array}{c}\text { EDS } \\
\text { Standard } \\
\text { sample }\end{array}$ & $\begin{array}{c}\text { EDS } \\
\text { Interface }\end{array}$ & $\begin{array}{c}\text { EDS } \\
\text { Standard } \\
\text { sample }\end{array}$ & $\begin{array}{c}\text { EDS } \\
\text { Interface }\end{array}$ & $\begin{array}{c}\text { EDS } \\
\text { Standard } \\
\text { sample }\end{array}$ \\
\hline A & $92.1 \pm 2.2$ & $91.6 \pm 0.5$ & $7.2 \pm 1.1$ & $7.4 \pm 0.5$ & $0.7 \pm 0.2$ & $0.9 \pm 0.3$ & & - \\
\hline B & 79.8 & $79.7 \pm 0.5$ & 18.0 & $17.6 \pm 0.7$ & 2.2 & $2.7 \pm 0.4$ & & - \\
\hline $\mathrm{C}$ & $45.2 \pm 0.8$ & $46.0 \pm 0.4$ & $47.3 \pm 0.4$ & $46.5 \pm 0.9$ & $7.5 \pm 0.4$ & $7.5 \pm 0.5$ & & - \\
\hline $\mathrm{D}$ & 1.6 & $1.5 \pm 0.2$ & 4.2 & $4.0 \pm 0.4$ & 94.3 & $94.5 \pm 0.9$ & & - \\
\hline $\mathrm{E}_{1}$ & $60.4 \pm 2.4$ & $67.0 \pm 0.3$ & $32.5 \pm 4.6$ & $26.3 \pm 0.6$ & 2.6 & $2.3 \pm 0.3$ & 4.6 & $4.4 \pm 0.1$ \\
\hline $\mathrm{E}_{2}$ & 70.8 & $67.0 \pm 0.4$ & 15.9 & $14.6 \pm 0.5$ & 0.9 & $0.8 \pm 0.3$ & 12.4 & $17.6 \pm 0.1$ \\
\hline
\end{tabular}

\section{Electrochemical Test}

Open Circuit Potential. The open circuit potential $\left(E_{\text {corr }}\right)$ of metal/ceramic interface and its constitutive layers was monitored during $60 \mathrm{~min}$ before of EIS and potentiodynamic polarisation tests. Fig. 2, shows the evolution of $\mathrm{E}_{\text {corr }}$ with the time for all samples. As comparison, pure Ti is also presented. As it can be observed in Fig. 2, most of the samples reach the steady-state at short immersion times. Pure $\mathrm{Ti}$ and layer $\mathrm{D}$ show the noblest potentials, indicating the formation of a passive layer thermodynamically more stable when compared with the other samples. On its turn, layer $\mathrm{B}$ and the $\mathrm{M} / \mathrm{C}$ interface reveal an intermediate $\mathrm{E}_{\text {corr }}$ curve situated above the other samples (layers $\mathrm{A}, \mathrm{C}, \mathrm{E}_{1}$ and $\mathrm{E}_{2}$ ). 


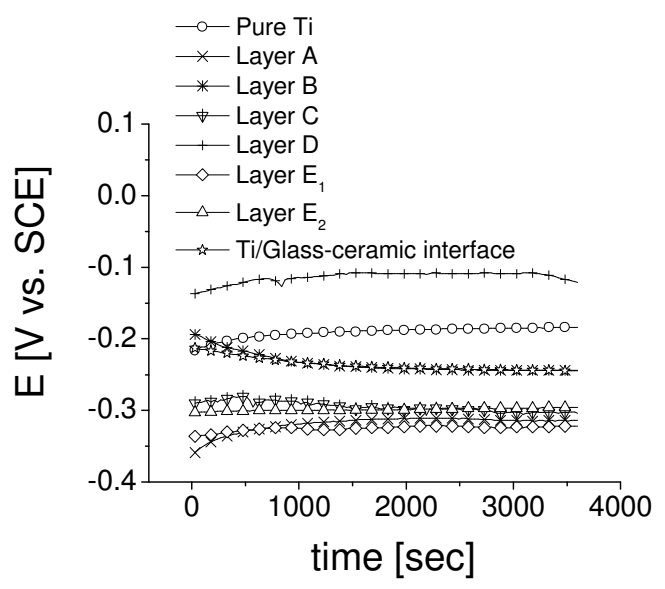

Fig. 2: Evolution of corrosion potential of the Ti/Glass-ceramic interface and its constitutive layers.
Electrochemical Impedance Spectroscopy

Test. Figures 3 show representative electrochemical impedance diagrams obtained in the Ti/Glass-ceramic interface and its constitutive layers after 10 days of immersion in HBSS. As it can be seen, pure Ti, and Ti-rich layers $\left(\mathrm{A}, \mathrm{B}, \mathrm{E}_{1}\right.$ and $E_{2}$ ) have the higher impedance values when compared with the $\mathrm{Cu}$ - and $\mathrm{Ag}$-rich layers $(\mathrm{C}$ and D) and the $\mathrm{M} / \mathrm{C}$ interface, i.e. Ti-rich layers evidence a superior corrosion resistance in comparison to the other layers. In fact, in the low and middle frequency ranges, the Bode impedance diagram (Fig. 3a) for Ti-rich layers, display a linear slope of about -1 as frequency decreases. At the same time, the phase angle values in Bode phase diagram (Fig. 3b) approach

$-90^{\circ}$. This is the characteristic response of a capacitive behaviour (high corrosion resistance) of a compact passive film, observed over nearly the whole measurement frequency range for pure Ti and Ti-rich layers.
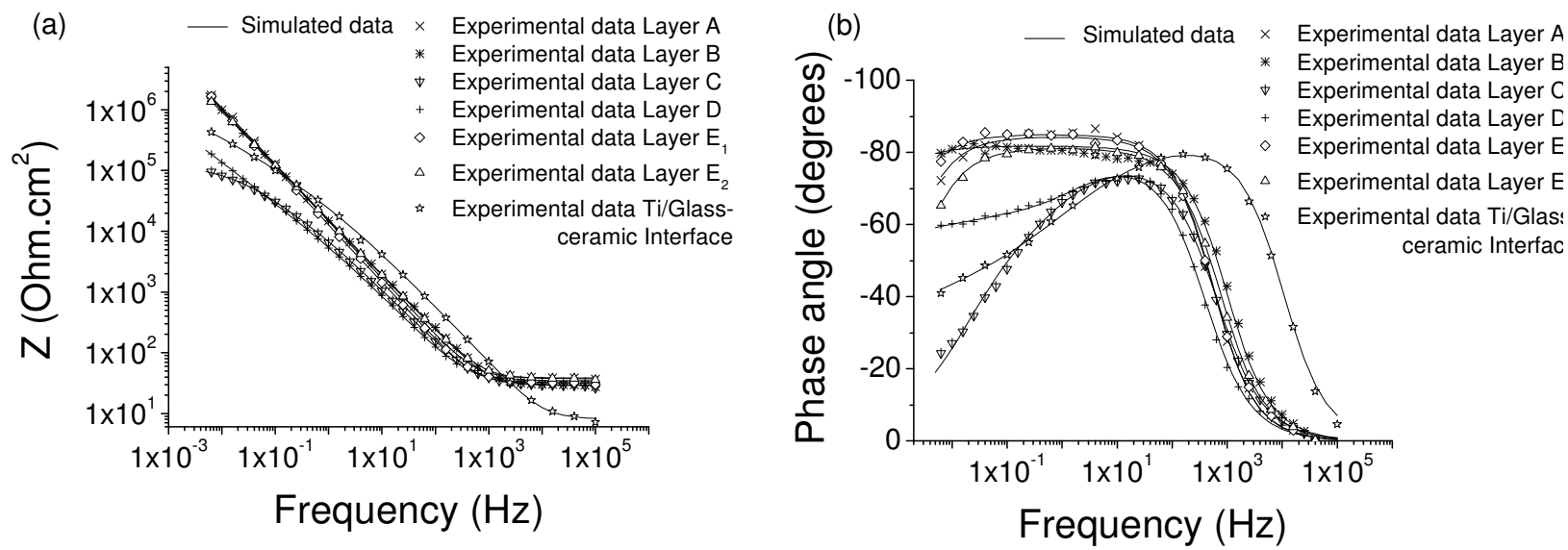

Fig. 3: Bode impedance (a) and Bode phase (b) plots obtained in Ti/Glass-ceramic interface and its constitutive layers after 10 days of immersion in HBSS.

Results of EIS experiments were modelled by an electrochemical equivalent circuit that describes the corrosion behaviour of each sample. In this work, a simple equivalent circuit, associated to the existence of a compact passive film, composed by the electrolyte resistance $\left(\mathrm{R}_{\mathrm{e}}\right)$ in series with a pair of elements in parallel (resistance and capacitance) was proposed for the pure $\mathrm{Ti}$ and for all Ti-rich layers (A, B, $\mathrm{E}_{1}$ and $\mathrm{E}_{2}$ ). This model was proposed by de Wit [4], and it was also assumed by Gonzales [5] to describe the corrosion behaviour of pure Ti and some Ti alloys used in biomedical applications. However, for the Ti/Glass-ceramic interface and for the other layers (C and D), a similar equivalent circuit, but now containing a second pair of elements was proposed. In both models, the first pair is composed by the capacitance of the passive film $\left(\mathrm{C}_{\mathrm{pf}}\right)$ and by the resistance of the passive film $\left(\mathrm{R}_{\mathrm{pf}}\right)$. The second pair, added to indicate the presence of defects in the passive film, for example, porosity; is related with the charge transfer processes at the passive film, and is composed by the same electric elements: the double layer capacitance $\left(\mathrm{C}_{\mathrm{dl}}\right)$ and the charge transfer resistance of the same $\left(\mathrm{R}_{\mathrm{ct}}\right)$. As it can be observed in figures $3 \mathrm{a}$ and $3 \mathrm{~b}$, a good agreement between the fitted and the experimental EIS data was obtained. 
Fig. 4a shows the evolution of the polarization resistance $\left(\mathrm{R}_{\mathrm{p}}\right)$ with the immersion time of the $\mathrm{M} / \mathrm{C}$ interface and its constitutive layers. This parameter was deduced from the EIS data simulation and calculated by the sum of $\mathrm{R}_{\mathrm{pf}}$ and $\mathrm{R}_{\mathrm{ct}}$. As it can be seen in Fig. 4a, pure Ti and Ti-rich layers, show the better corrosion resistance, as revealed by the higher $R_{p}$ values, which appears to be slightly improved with the immersion time. In contrast, the $\mathrm{Cu}$-rich layer $(\mathrm{C})$, shows the lower corrosion resistance. In fact, the $\mathrm{R}_{\mathrm{p}}$ of this last layer is low and remains almost constant during the immersion time, this being an indication of thermodynamic instability of the passive layer formed on the surface of this layer. On the other hand, Ti/glass-ceramic interface shows intermediate $R_{p}$ values between the Ti-rich layers and the $\mathrm{Cu}$ - and $\mathrm{Ag}$-rich layers. This behaviour can be attributed to a mixed effect of the individual microstructures and chemical compositions of the individual layers constitutive of the interface.
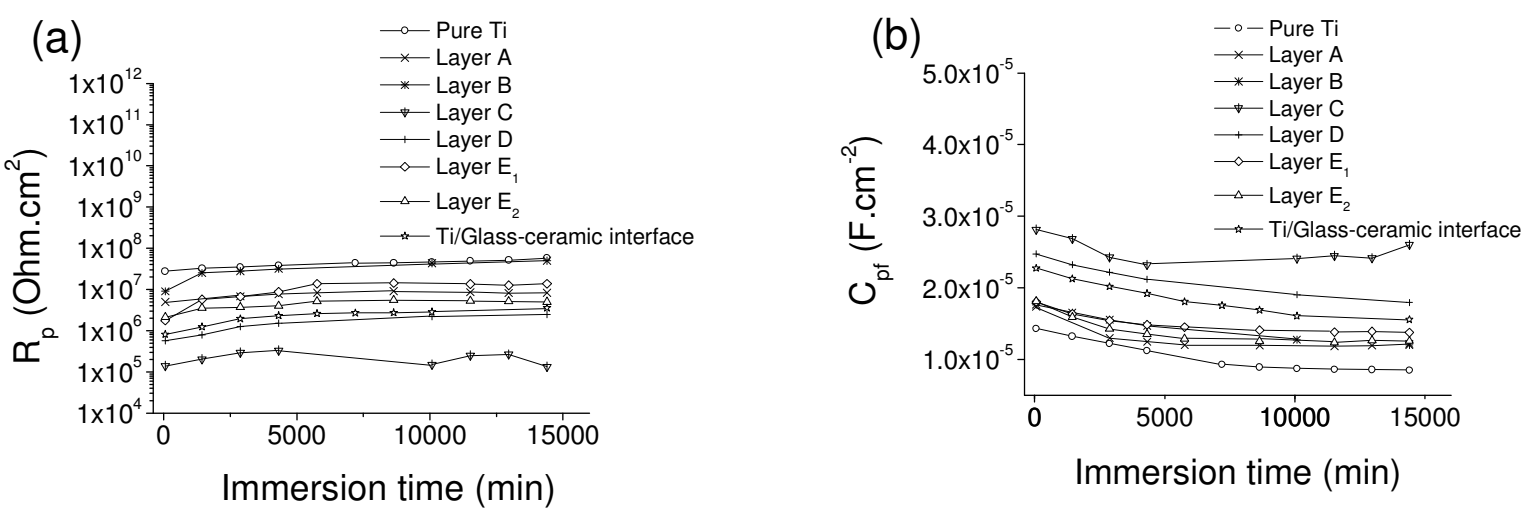

Fig. 4: Evolution of the polarization resistance- $\mathrm{R}_{\mathrm{p}}(\mathrm{a})$ and the capacitance of the passive film- $\mathrm{C}_{\mathrm{pf}}(\mathrm{b})$ in Ti/Glass-ceramic interface and its constitutive layers with the immersion time.

Regarding the protective character of the passive films, it can be evaluated by the capacitance of the passive film $\left(\mathrm{C}_{\mathrm{pf}}\right)$, which represents the dielectric characteristics of the film. In general terms, a film promotes a better protective character when it has a low capacitance (low dielectric constant). Fig. $4 \mathrm{~b}$, shows the variation of the $\mathrm{C}_{\mathrm{pf}}$ with the immersion time. As it can be seen, $\mathrm{C}_{\mathrm{pf}}$ slightly decreases during the first moments of immersion and then stabilizes, indicating a long-term stability of the passive film. In contrast, the slight enhancement along the time, and the higher $\mathrm{C}_{\mathrm{pf}}$ values obtained for the layer $\mathrm{C}$, when compared with the other samples, shows the poor protective character and the lower thermodynamic stability of this film in terms of corrosion, as also demonstrated by the low $R_{p}$ values (see Fig. 4a). Once more, the $M / C$ interface shows intermediate $\mathrm{C}_{\mathrm{pf}}$ values between the Ti-rich layers and the $\mathrm{Cu}$-and Ag-rich layers (layers $\mathrm{C}$ and $\mathrm{D}$, respectively), revealing that the individual contribution of the constitutive layers play an important role in the whole corrosion behaviour of the interface.

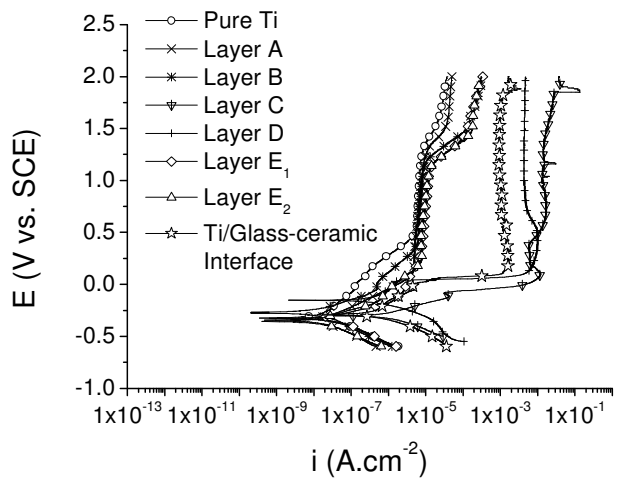

Potentiodynamic Polarisation Test. Results of potentiodynamic polarisation tests are in good agreement with the EIS results. As it can be seen in Fig. 5, all samples, including the $\mathrm{M} / \mathrm{C}$ interface, reveal a clearly defined passive region. The lowest passive current densities of pure $\mathrm{Ti}$ and all Ti-rich layers are a good indication of the high corrosion resistance of these samples. On the other hand, layers $\mathrm{C}$ and $\mathrm{D}$ show the lowest corrosion resistance and, the $\mathrm{M} / \mathrm{C}$ interface shows an intermediate passive current density between the Ti-rich layers and the $\mathrm{Ag}$ - and $\mathrm{Cu}$-rich layers.

Fig. 5: Anodic polarisation curves of Ti/glass-ceramic interface and its constitutive layers. 
The morphology of the interface and some of its constitutive layers obtained after potentiodynamic polarisation tests is presented in Fig. 6. As it can be seen in Fig. 6b, layer C, in accordance with the low $R_{p}$ and the high $C_{p f}$ (see Fig. 4) and with the high passive current density (see Fig. 5), shows a strong degradation of its surface after the corrosion test. The degradation of this layer consists in the attack of the $\mathrm{Cu}$-rich regions of the microstructure, resulting in a strong release of copper. In contrast, layer D (see Fig. 6c), which is rich in Ag, is totally covered by a film identified as silver chloride. This passive film was also identified in a big extension of the surface of the interface (see Fig. 6a) and its high $\mathrm{E}_{\text {corr }}$ (see Fig. 2) shows the high thermodynamic stability which contribute to protect the whole $\mathrm{M} / \mathrm{C}$ interface.
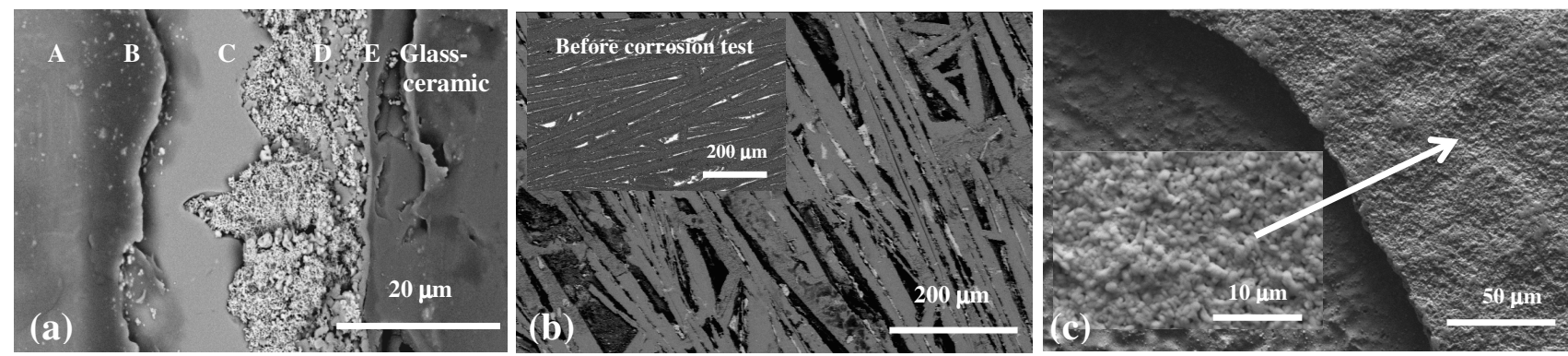

Fig. 6: Morphology of Ti/glass-ceramic interface (a) and some of its constitutive layers (layer C (b) and layer D (c)) after potentiodynamic polarisation test.

\section{Conclusions}

EIS has found its usefulness for studying the corrosion behaviour of metal/ceramic interfaces. Both, EIS and potentiodynamic polarisation results are in good agreement and showed that corrosion resistance Ti/glass-ceramic interface is strongly influenced by the chemical composition of its individual layers. Ti-rich layers and especially $\mathrm{Ag}$ - and $\mathrm{Cu}$-rich layers play an important role in the corrosion mechanism of the whole interface. Passive behaviour of the $\mathrm{M} / \mathrm{C}$ interface seems to be related with the characteristics of the oxide passive film formed onto Ti-rich layers surfaces as well as to the preferential reaction of Ag-rich layer with the chloride containing in the physiological solution. This last reaction gives origin to an $\mathrm{AgCl}$ passive film covering all the other interfacial layers and avoid further degradation of the interface. Simultaneously, obtained results suggest that the $\mathrm{Cu}$-rich layer can be the main responsible for the $\mathrm{Cu}$ release from the interface and for the degradation of whole system. Thus, great efforts should be carried out in order to develop brazing alloys free of detrimental elements, such as $\mathrm{Cu}$, which appears to be the main responsible for the degradation process occurring in $\mathrm{M} / \mathrm{C}$ joints produced by active metal brazing methodologies.

\section{Acknowledgements}

The authors acknowledge the financial support provided by Fundação para a Ciência e a Tecnologia (FCT), Portugal (projects POCTI/CTM/33384/2000 and SFRH/BPD/5518/2001).

\section{References}

[1] O. Paiva, Ligação Metal/Cerâmico: Tecnologia e Caracterização, PhD’s Thesis, Universidade do Porto, Portugal, 2000.

[2] L.A. Rocha, T.O. Ferreira, A.C. Monteiro: Key Engineering Materials Vol. 230-232 (2002), p. 479.

[3] L.A. Rocha: Development of a hermetic metal/ceramic encapsulation system for injectable telemetric electronic devices; PhD’s Thesis, Universidade do Minho, Portugal, 1996.

[4] E.P.M. van Westing, G.M. Ferrari, D.H. van der Weijde, J.H.W. de Wit, Corros. Sci. Vol. 34 (1993), p. 937.

[5] J.E.G. Gonzalez, J.C. Mirza-Rosca, Journal of electrochemical chemistry, Vol. 471 (1999), p. 109. 